\title{
AN INVESTIGATION OF CORROSION OF FRICTION WELDED AND POST-WELD HEAT-TREATED AA6061/SIC/GRAPHITE HYBRID COMPOSITES
}

\author{
Jadamuni SenthilkumaR ${ }^{a, *}$, Pavan S. M. KumaR ${ }^{b}$, \\ MANICKAM BALASUBRAMANIAN ${ }^{c}$ \\ a Sathyabama Institute of Science and Technology, Department of Mechanical Engineering, Sholinganallur, \\ 600119 Chennai, India \\ ${ }^{b}$ Anand Institute of Higher Technology, Department of Mechanical Engineering, Kazhipattur, 603103 Chennai, \\ India \\ ${ }^{c}$ RMK College of Engineering and Technology, Department of Mechanical Engineering, Puduvoyal, \\ 601206 Chennai, India \\ * corresponding author: jsenthil_trt@rediffmail.com
}

\begin{abstract}
The aluminium-based hybrid metal matrix composites have noteworthy applications in sub-sea installations, structures of deep-sea crawlers, submarine parts, engine cylinders, drum brakes etc., as they possess high strength, corrosion resistance, chemical, and dimensional stability. In this investigation, the pitting corrosion behaviour of friction welded and post-weld heat-treated AA6061/SiC/graphite hybrid composites were analysed. The corrosion rates of AW (as welded), ST (Solution treated), STA (Solution treated and Aged), and AA (Artificially Aged) weld joints were experimentally determined. The corrosion behaviour has been discussed in light of microstructure. The experimental results revealed that the STA joints exhibited better corrosion resistance characteristics as compared to AW, AA, and ST joints. The corrosion rate was high for AW joints, followed by AA and ST joints, respectively. Taking into account the corrosion rates of AW and STA joints, the STA joints have a corrosion rate $34.6 \%$ lesser than that of AW joints. A comparison of AA and ST with STA joints reveals that the rate of corrosion for STA joints was $31.1 \%$ lesser than that of AA joints and $28.8 \%$ lesser than that of ST joints. A lower corrosion rate was observed for STA joints as compared to $\mathrm{AA}, \mathrm{AW}$, and ST joints.
\end{abstract}

KEYWORDs: Corrosion, aluminium, friction welding, PWHT, hybrid composite.

\section{INTRODUCTION}

Aluminium based hybrid metal matrix composites have promising applications in engine cylinder blocks, pistons, disc brakes, aircraft wing panels, etc., as they possess high strength, corrosion resistance, chemical stability, dimensional stability at high temperature [1].

Solidification cracking, hot tearing, and fissuring are some common defects observed in fusion joints of aluminium alloys. These undesirable features in the welded joints could be eliminated by using a solidstate welding process like continuous drive friction welding [2]. Nunes et al. investigated the corrosion behaviour of silicon carbide- aluminium metal matrix composites. The cathodic oxygen reduction process was the main driving force for the corrosion process. In $\mathrm{Al}-\mathrm{Si}-\mathrm{Mg}$ composites, eutectic silicon, $\mathrm{SiC}$ particles, and the precipitated phases prove to be the active cathodic sites for the corrosion process. Pitting resistance can be improved through anodization and application of ceria coatings [3]. Mclntyre et al. investigated the pitting behaviour of aluminium- $\mathrm{SiC}_{\mathrm{w}}$ composites. Pit nucleation takes place due to the presence of $\mathrm{SiC}$ intermetallic. The intermetallic tends to form at dislocations, voids, and grain boundaries. The
$\mathrm{SiC}_{\mathrm{w}}$ can act as efficient nucleation sites for intermetallic formations in $\mathrm{SiC} / \mathrm{AA} 2124$ composites [4]. The pitting behaviour of $\mathrm{Gr}-\mathrm{Al}$ and $\mathrm{SiC}-\mathrm{Al}$ metal matrix composites has been examined. The corrosion resistance of the unreinforced alloy is more compared with reinforced alloy in 5. Galvanic corrosion behaviour of aluminium matrix composites reveals the aluminium coupled to graphite fibre in aerated $3.15 \mathrm{wt} \% \mathrm{NaCl}$ shows a high corrosion current density value, which in turn possesses a low corrosion rate [6]. After the friction welding process, AA6061/SiC/graphite hybrid composites show $\mathrm{Mg}_{2} \mathrm{Si}$ as the predominant precipitate present in all the joints [7. Sori won et al. studied the corrosion behaviour of friction welded dissimilar aluminium alloys. An improvement in the corrosion performance was observed in AA6063 due to the growth of the passivation layer [8]. If corrosion potential is more positive, pitting corrosion is initiated in aluminium alloy matrix. Mathematical models can be used for the prediction of accurate results [9]. Abhishek Sharma et al. reported that Al6061-SiC-graphite hybrid surface composite has an improved corrosion resistance property due to the decrease of interfacial corrosion. This can be attributed to a graphite layer formation 
that behaves as a passive layer, which resists the corrosion [10. The hot extrusion produces a high level of deformation in Al6061-SiC-graphite composites that produces improved mechanical and microstructural properties. An extruded component has the least corrosion rate [11]. Sriram Vikas et al. studied the influence of post-weld heat treatment (PWHT) and pitting corrosion behaviour of dissimilar aluminium alloy friction stir welds. All the regions of the weld have an improved pitting resistance after PWHT (Post Weld Heat Treatment). This can be attributed to the precipitation of fine sub microscopic particles during natural ageing. Active sites for the pit initiation get reduced due to the dissolution of secondary intermetallic precipitation 12. Sunitha et al. reported that Al6065/SiC/graphite hybrid composites show a good corrosion resistance behaviour if the graphite percentage of the composite is low [13. Subba Rao et al. reported the influence of heat treatment on the corrosion behaviour of aluminium metal matrix composites. Cast composites show larger size pits in more numbers compared to heat-treated composites. This indicates that a cast composite has a poor corrosion resistance. Heat-treated composites show reduced sized pits in a lesser number, which in turn has a role in corrosion minimization [14. The intermetallic phases in the aluminium alloys prove to be the regions where localized form of corrosion occurs. The corrosion behaviour is influenced by intermetallic phases in reinforced alloys [15]. The corrosion behaviour of AA7075 aluminium alloy friction stirs welds after PWHT has been examined. The size and interspaces of the precipitates influence the pitting corrosion. Large spacing and discontinuous precipitates reduce the susceptibility to pitting corrosion. The finer grains and continuous precipitates promote pitting corrosion [16]. The corrosion behaviour of AA7075 aluminium metal matrix composites was studied in a $3.5 \mathrm{wt} \% \mathrm{NaCl}$ aqueous solution. For low $\mathrm{pH}$ values (i.e., acidic), the corrosion rate was larger. As far as volume percentage goes, the corrosion rate lowered due to the increase in the content of reinforcement 17. Trzaskoma investigated the pit morphology of aluminium alloy and silicon carbide/aluminium alloy metal matrix composites. The composites have a greater number of pit initiation sites than the alloy due to a greater number of intermetallic phases present in the composite. A large number of detrimental intermetallic phases found on the composites leads to the formation of more pits on the composite. The metal dissolution rates are larger in the case of the composite as compared to the alloy [18]. Bhat et al. investigated the corrosion behaviour of silicon carbide particles reinforced with $6061 \mathrm{Al}$ alloy composites. The composites corrode in a faster manner than the base alloy due to the interface of the reinforcements that result in crevices or pits. This could be attributed to the fact that a thin layer of reaction product present at the interface acts as an effective cathode that enables a higher corrosion rate. The homogeneity in the distribution of particles and the absence of defects like pores in the extruded composites make it less susceptible to corrosion [19]. Sunil sinhmar et al. investigated the corrosion behaviour of a friction stir weld joint of AA2014 aluminium alloy. Due to the dynamic recrystallization and plastic deformation experienced during the welding, grain refinement happened in the weld zone. The dissolution and coarsening of the precipitates increase the corrosion loss. The precipitate free zones act as anodes and increase the corrosion loss. The precipitate free zones are comparatively soft [20]. Farhad Gharavi et al. analysed the corrosion behaviour of friction stir welded lap joints of AA6061-T6 aluminium alloy. The localized corrosion attack generated by semi-pittingand circumferential pits were formed around strengthening precipitates. The higher number of intermetallic particles leads to cathodic reactions. The corrosion resistance of weld regions was poorer as compared to the parent alloy [21. Sara Bocchi et al. investigated the influence of process parameters on the corrosion behaviour of friction stir welded aluminium joints. During the welding, process orientation is produced in the grain structure. The coarsening precipitates and dissolution of precipitates enhanced the corrosion loss [22]. Vinoth jebaraj et al. analysed the corrosion behaviour of aluminium alloy 5083 and its weldment for marine applications. The second phase particles enriched with $\mathrm{Mg}$ have been formed during the weld. The parent metal exhibited a better corrosion resistance as compared to the weldment [23]. Ramesh et al. studied the experimental erosion-corrosion analysis of friction stir welding of AA5083 and AA6061 for sub-sea applications. The erosion was the highest for the basic material, followed by a decrease with decreasing $\mathrm{PH}$ values. The corrosion and erosion were more in the centre of the welding as compared to the base material [24]. Shuai Li et al. made experimental studies on the corrosion behaviour and mechanical properties of $\mathrm{Al}-\mathrm{Zn}-\mathrm{Mg}$ aluminium alloy weld. The comparison made between the base metal and weld joints revealed that the base metal possesses superior mechanical properties. The variance in corrosion potential depends on the number of precipitates and the difference in the composition of constituents [25].

\section{EXPERIMENTAL DETAILS}

\subsection{Materials}

AA6061 aluminium alloy was used as the matrix material. Silicon carbide with a weight fraction of $10 \%$ was used as the primary reinforcement and graphite was used as the secondary reinforcement with a weight fraction of $5 \%$. The chemical composition of AA6061 is given in Table 1.

\subsection{FABRICATION OF COMPOSITES}

The stir casting process was used to fabricate the cast samples. AA6061 alloy billets were melted at $650{ }^{\circ} \mathrm{C}$ 


\begin{tabular}{ccccccccc}
\hline $\mathrm{Mg}$ & $\mathrm{Si}$ & $\mathrm{Fe}$ & $\mathrm{Cu}$ & $\mathrm{Cr}$ & $\mathrm{Mn}$ & $\mathrm{Zn}$ & $\mathrm{Ti}$ & $\mathrm{Al}$ \\
\hline 0.9 & 0.62 & 0.33 & 0.28 & 0.17 & 0.06 & 0.02 & 0.02 & $\mathrm{Bal}$ \\
\hline
\end{tabular}

TABle 1. Chemical composition(wt.\%) AA6061.

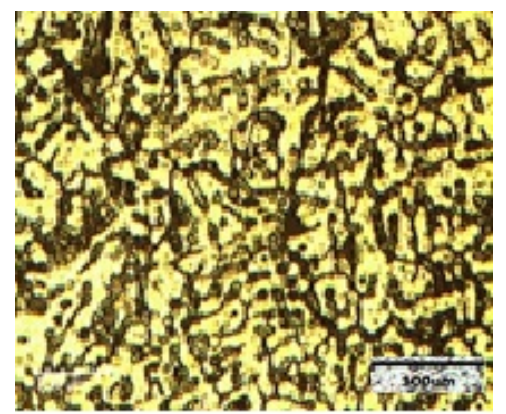

FiguRE 1. Al matrix before extrusion.

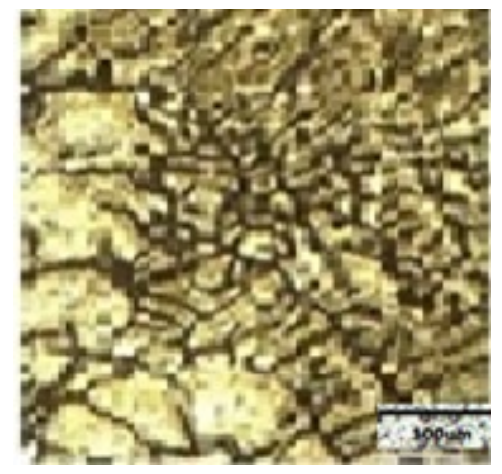

FIGURE 2. Al matrix after extrusion.

At this stage, pre-heated particles of $\mathrm{SiC}$ and graphite were added and samples were cast. The samples were then subjected to machining and specimens of $45 \mathrm{~mm}$ length and $16 \mathrm{~mm}$ diameter were produced. Then, the process of hot extrusion was carried out at a temperature of $450{ }^{\circ} \mathrm{C}$. After the extrusion process, specimens of increased length and decreased diameter were obtained. The extruded specimens after machining had final dimensions of $60 \mathrm{~mm}$ in length and $12 \mathrm{~mm}$ in diameter. The Fig. 1 shows the aluminium matrix before the extrusion and Fig. 2 shows the aluminium matrix after the extrusion.

\subsection{FRICTION WELDING}

The extruded specimens were joined in a continuous drive friction welding machine (model: SPM-FW-3T) as shown in Fig. 3 In this friction welding machine, clamping was done by a hydraulically controlled chuck. The machine was inbuilt with a data acquisition and analysis software. The maximum speed of the machine spindle was $2000 \mathrm{rpm}$. Friction welding was carried out at a rotational speed of $1600 \mathrm{rpm}$ and an upset load of $3.5 \mathrm{kN}$ for 3 seconds. In total, 32 joints were done and the friction welded joints are shown in Fig. 4. The Fig. 5 shows the As welded condition (AW) cov-

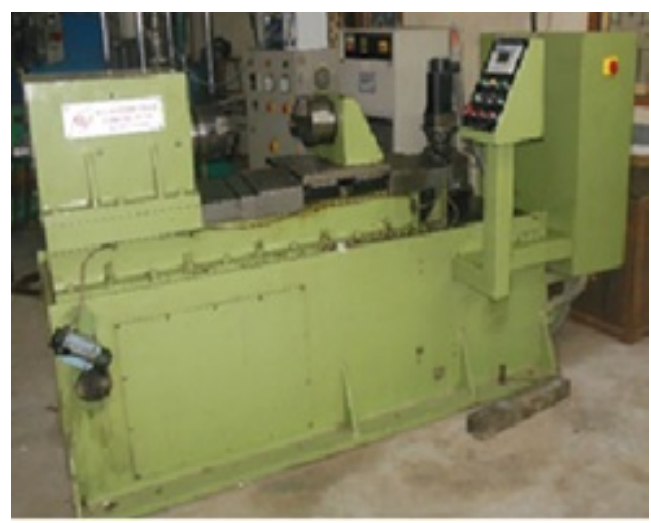

FIGURE 3. Friction welding machine.

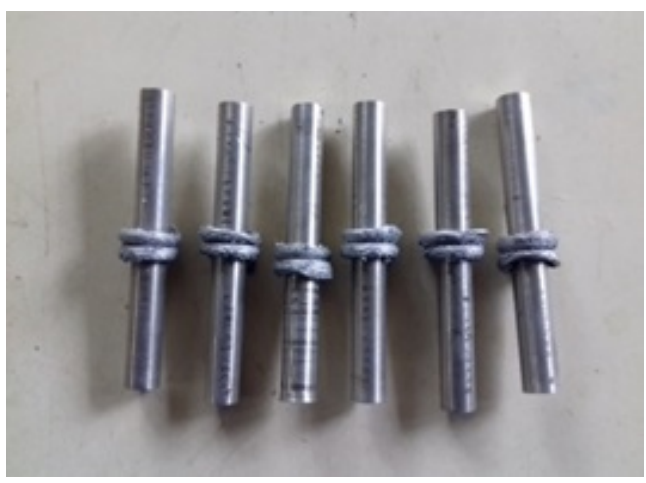

Figure 4. Friction welded samples.

ering Parent metal (PM), Heat affected Zone (HAZ) and Weld Zone (WZ).

\subsection{Post Weld heat TREATMEnt}

Eight joints were isolated and kept in the aswelded (AW) condition without a post-weld heat treatment. The remaining joints were kept in a muffle furnace for the heat treatment as shown in Fig. 6. Solution treatment (ST) was performed on eight joints at a temperature of $525^{\circ} \mathrm{C}$. The joints were quenched in water after a 1-hour soaking period in the furnace. Eight specimens were subjected to the solution treatment followed by artificial ageing (STA), wherein the solution-treated samples were aged at $163^{\circ} \mathrm{C}$ for 8 hours. The remaining eight specimens were subjected to artificial ageing at a temperature of $163{ }^{\circ} \mathrm{C}$ for 8 hours and then let to cool in the furnace itself. The post-weld heat-treated samples are shown in Fig. 7.

\subsection{Corrosion test}

Gill AC Potentiostat was used to carry out the corrosion test. It has a $100 \mathrm{kHz}$ frequency response. It has up to $2 \mathrm{Amp}$ in same style enclosure. All the 


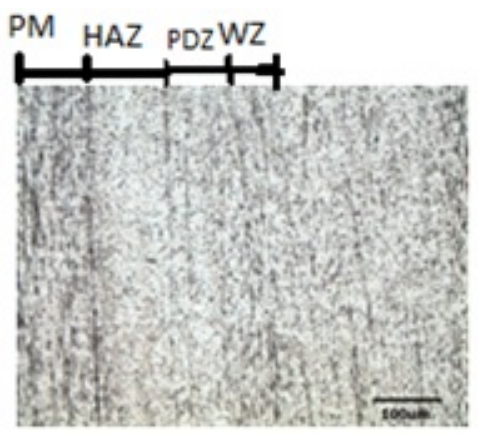

Figure 5. AW covering Parent metal, Heat affected Zone, Weld Zone.

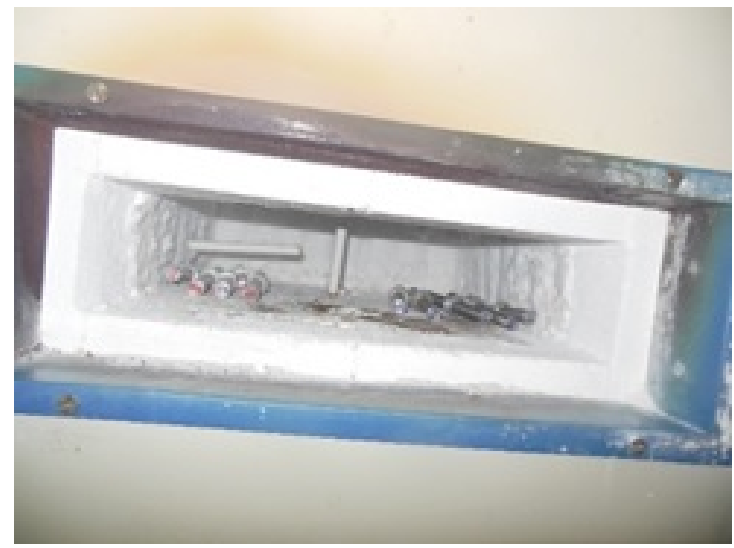

Figure 6. Post weld samples in the furnace.

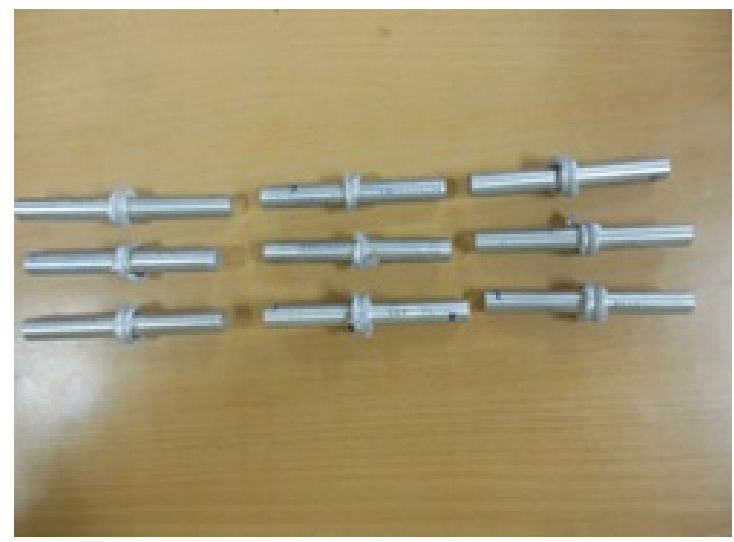

Figure 7 . Post weld heat treated samples.

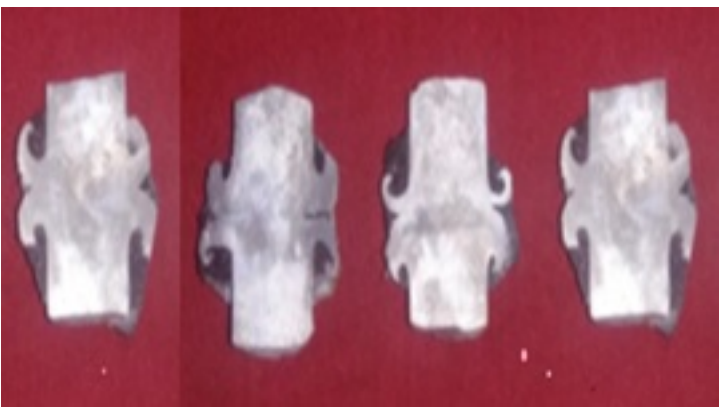

Figure 8. Specimens after the corrosion test.

specimens were ground on-grid emery paper to have a uniform standard surface. Acetone was used to clean the specimens' surfaces before the exposure to the solution of 3.5 wt. $\%$ of $\mathrm{NaCl}$. The Fig. 8 shows the specimens after the corrosion test. The specimens were cleaned and dried according to ASTM STP 534 after the corrosion tests.

\subsection{Microstructure ANALYSis}

The optical micrographs of the weld zones were captured for AW, ST, STA, and AA joints using standard metallographic procedures. The etchant used is Keller's reagent. The microstructural analysis was performed using a $100 \mathrm{~W}$ halogen powered optical microscope (model:MM-400/800), with a maximum magnification range of $10 \times$ to $400 \times$.

\section{Results AND Discussion}

\subsection{Microstructure of WeLd REgions}

Fig. 9a shows the weld region of the AW sample. The weld region shows eutectic particles along with primary aluminium grains. The micro voids were present in the vicinity of grain boundaries. The grain structure seems to be coarse in this AW sample and the distribution of the reinforcement was also not uniform. The coarse grain structure can be attributed to the effect of severe heat generated during the friction welding process. Fig. $9 \mathrm{~b}$ shows the weld region of the AA condition. The microstructure shows longer primary $\alpha$-aluminium grains with eutectic particles. The agglomeration of Silicon carbide particles can be seen from the microstructural image. Due to the postweld heat treatment process, the grain structure has been improved. Fig. 9c shows the microstructure of the weld region of the ST condition. The microstructure shows fine acicular primary $\alpha$-aluminium with eutectic particles near the grain boundaries. A fine grain structure was visible. A uniform distribution of reinforcement particles can be seen from the microstructure.

Fig. $9 \mathrm{~d}$ shows the microstructure of the weld region of the STA condition. The microstructure shows the primary aluminium grains with eutectic particles precipitated along the grain boundaries. The frictional stress during the friction welding process has produced a perpendicular re-orientation in the grain structure. 


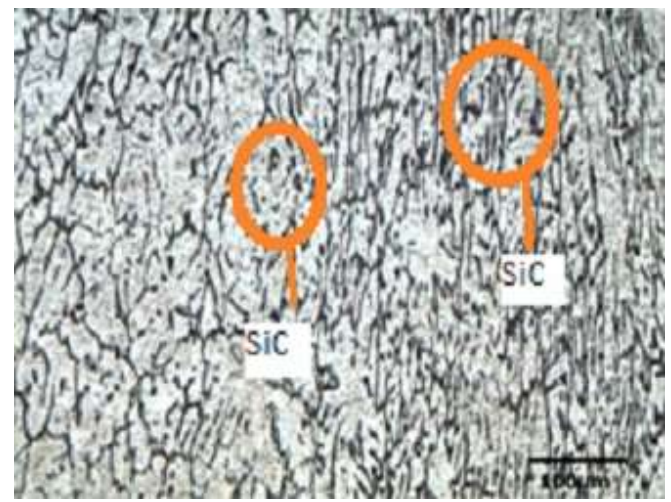

(A) . AW

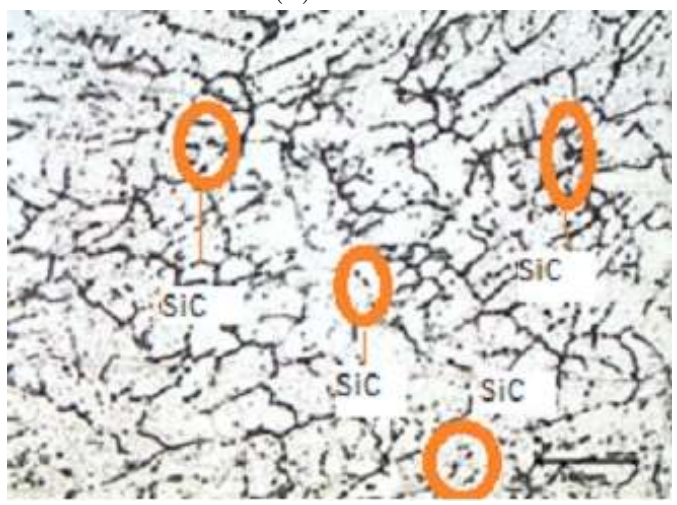

(c) . ST.

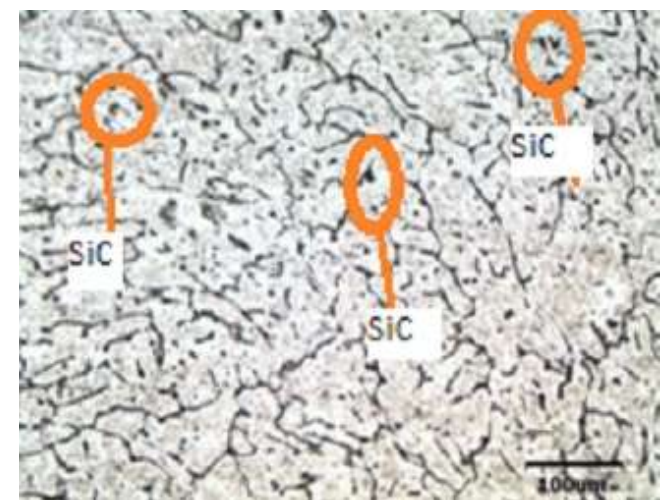

(B) . AA.

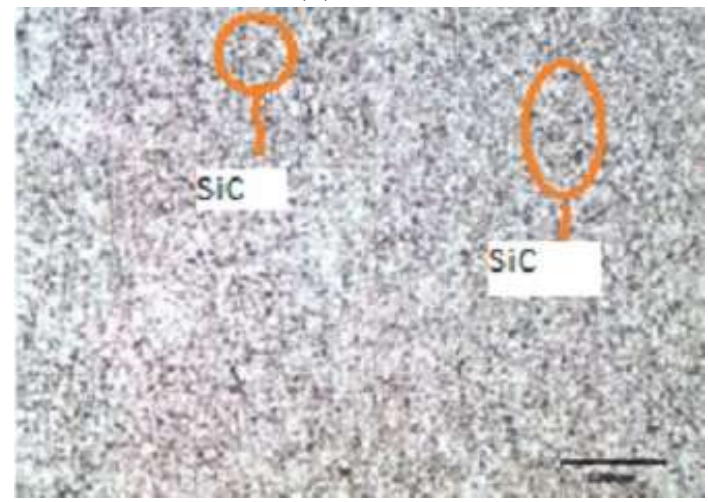

(D) . STA.

Figure 9. Microstructure of weld regions of the samples.

The grain boundary precipitates seem to be discontinuous and with large spacing between them. The homogenous distribution of reinforcement particles can be visualized from the microstructure. During the heat treatment process, the dissolution of secondary intermetallic precipitation took place and resulted in the formation of fine sub-microscopic particles in the structure. The Precipitates expected to form from this alloy are $\mathrm{Mg}_{2} \mathrm{Si}$ precipitates. The precipitate formation enhances the strength and corrosion resistance of the composite. Re-precipitation was observed to increase the hardness, while recrystallization of finer grains enhanced the strength.

\subsection{EleCtrochemicAl MEASUREMENT}

The potentiodynamic polarization test results conducted to analyse the corrosion behaviour of various joints of AW, AA, ST, STA are shown in Fig. 10 The corrosion potential (Ecorr) and corrosion current densities (Icorr) obtained by using Tafel extrapolation were shown in Table 2 The As-welded joints show a shifting of Ecorr towards more negative values. The rate of corrosion in the AW weld surface was found to be $9.735 \mathrm{~mm} /$ year. The rate of corrosion in the case of AA and ST joints was found to be $9.234 \mathrm{~mm} /$ year and $8.934 \mathrm{~mm} /$ year, respectively. A graphite layer gets formed between the $\mathrm{Al}$ and $\mathrm{SiC}$ interface that reduces the corrosion. Among the weld regions of different joints, the STA has shown a low corrosion rate. The rate of corrosion was found to be $6.368 \mathrm{~mm} /$ year.
An increased grain refinement seems to reduce the possibility of pitting corrosion.

\subsection{Corrosion Morphology of Weld REGIONS}

The pitting corrosion behaviour on the weld regions of AW, ST, STA, and AA is shown in Fig. 11. The corrosion morphology of the weld region of AW is shown in Fig. 11a The AW weld region shows a higher rate of corrosion attack due to more $\mathrm{SiC}$ inter-metallic particles in the interior grain and grain boundaries. A clustered attack can be seen around the intermetallic particles that can be ascribed to pitting corrosion. The SiC intermetallic, which gets formed at voids and grain boundaries results in the pit initiation. At the interface of the matrix and the reinforcement, the $\mathrm{SiC}$ intermetallic gets formed that acts as a cathode. The inter-metallic were continuous in this AW weld region, which in turn increases cathode-to-anode ratio that caused a higher corrosion rate.

The distribution of particles in this AW weld region seems to be non-uniform, hence the higher corrosion loss. Here, the grain coarsening had happened due to the severe heat generated during the friction welding process. The coarse grains promote corrosion. The microstructure of the weld region of AA is shown in Fig. $11 \mathrm{~b}$ The weld region shows the fine pitting corrosion that was caused by anode etching. The pitting spots were larger and resembled islands. The pitting spots were continuous, which resulted in a higher 


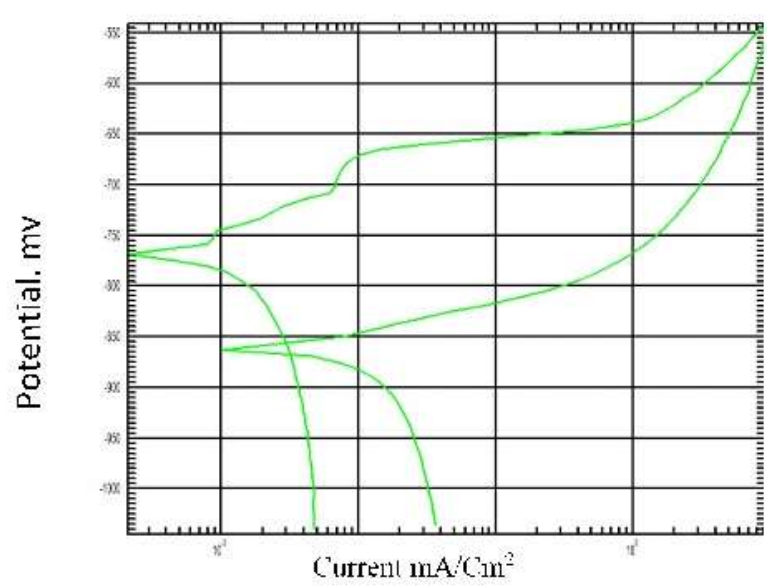

(A) . AW.

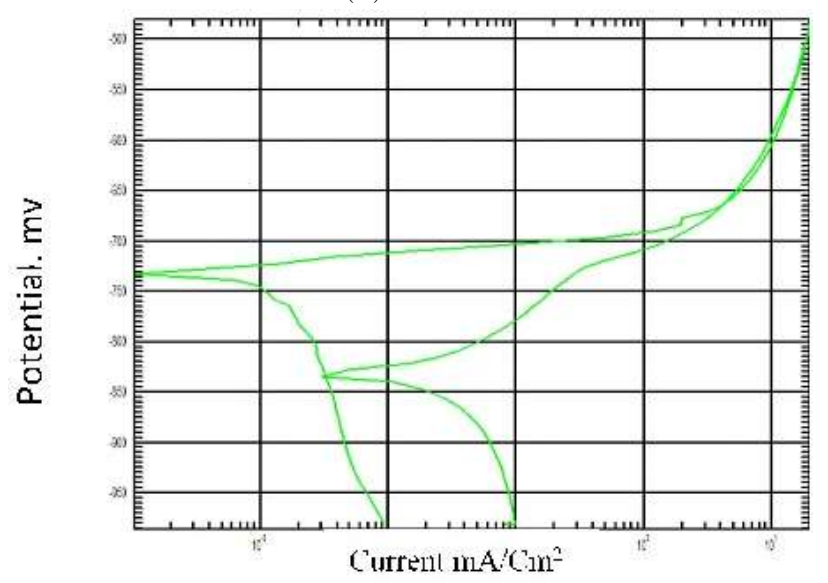

(c) . ST .

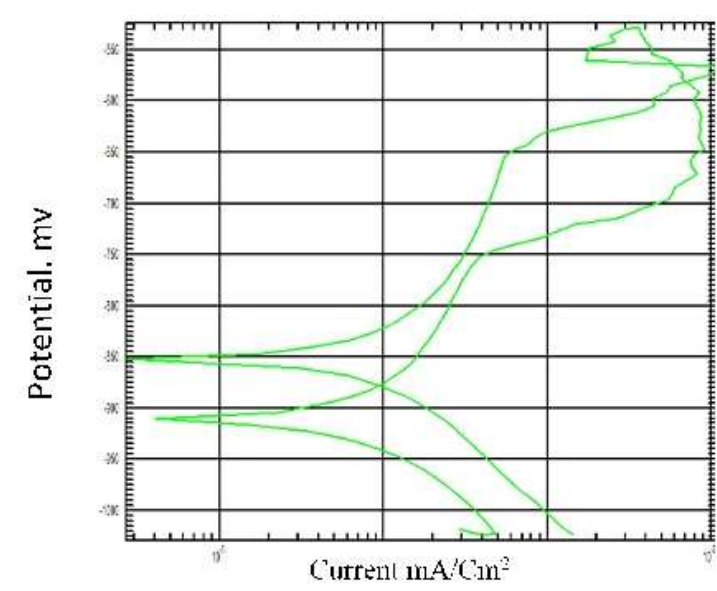

(B) . AA.

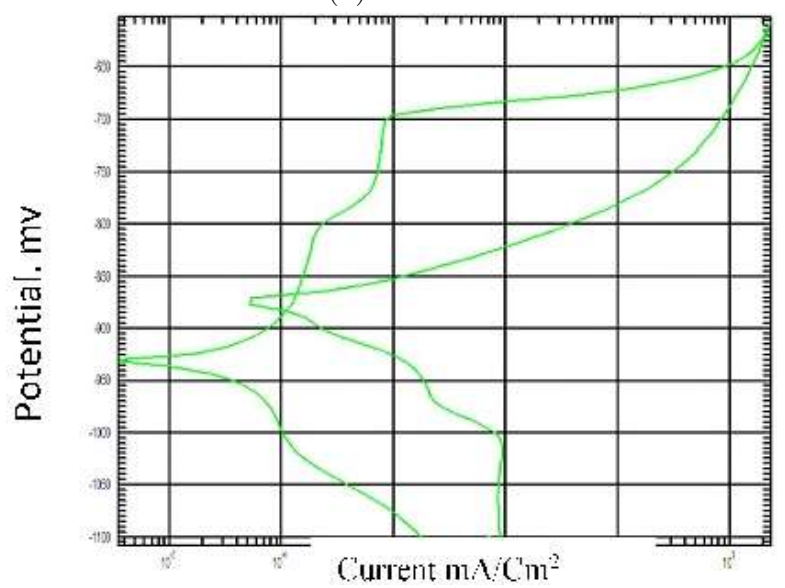

(D) . STA.

Figure 10. Potentiodynamic curves of different weld samples.

\begin{tabular}{lcccccc}
\hline S.No & $\begin{array}{c}\text { Starting } \\
\text { potential } \\
(\mathrm{mV})\end{array}$ & $\begin{array}{c}\text { Reverse } \\
\text { potential } \\
(\mathrm{mV})\end{array}$ & $\begin{array}{c}\text { Sweep } \\
\text { rate } \\
(\mathrm{mV} / \mathrm{min})\end{array}$ & $\begin{array}{c}\text { Rest } \\
\text { potential } \\
(\text { Ecorr }) \\
(\mathrm{mV})\end{array}$ & $\begin{array}{c}\text { Current } \\
\text { density } \\
(\text { Icorr }) \\
\left(\mathrm{mA} / \mathrm{cm}^{2}\right)\end{array}$ & $\begin{array}{c}\text { Corrosion } \\
\text { rate } \\
(\mathrm{mm} / \text { year })\end{array}$ \\
\hline AW & -250 & 250 & 100 & -793.09 & 1.8021 & 9.735 \\
AA & -250 & 250 & 100 & -775.98 & 1.6727 & 9.234 \\
ST & -250 & 250 & 100 & -733.3 & 1.5621 & 8.934 \\
STA & -250 & 250 & 100 & -653.67 & 1.2170 & 6.368 \\
\hline
\end{tabular}

TABLE 2. Results obtained from potentiodynamic plots. 


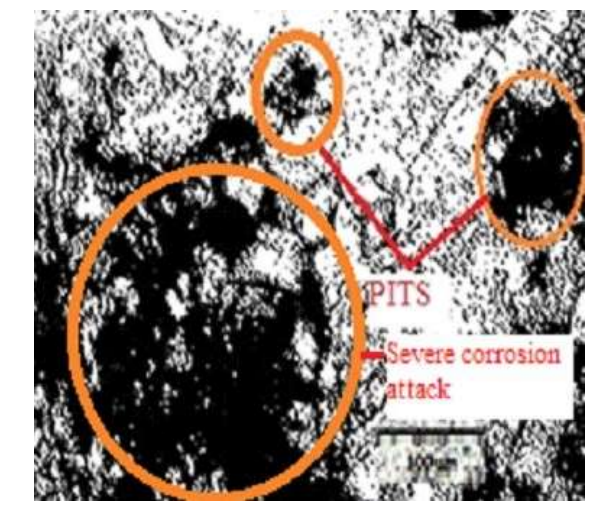

(A) . AW

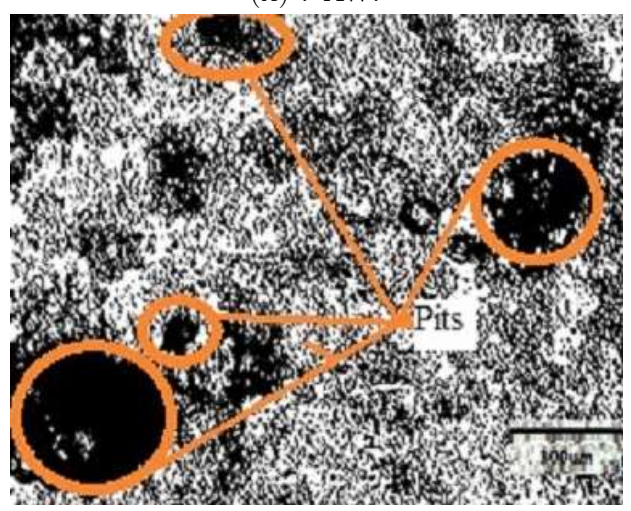

(c) . ST.

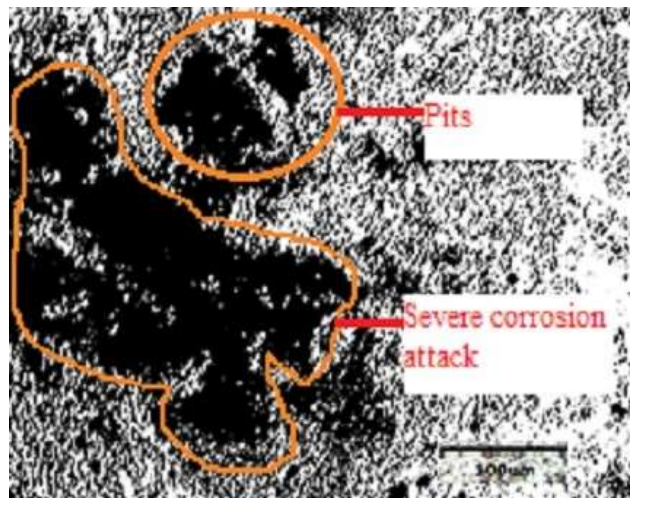

(B). AA.

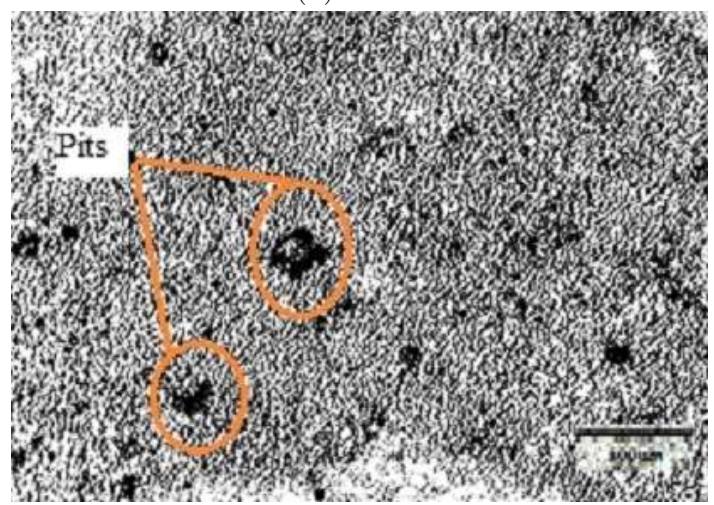

(D) . STA.

FiguRE 11. Corrosion morphology of different weld samples.

corrosion loss. The dark fine particles of graphite agglomerates were found on the weld surface of the AA specimen. The increase in corrosion loss, in this case, can be attributed to the porous nature of graphite particle agglomerates, which leads to the sucking of electrolytes. This, in turn, increases the corrosion current density, which ultimately increases the corrosion loss.

The weld region of the ST surface is shown in Fig. 11c The pits were caused by the etching process. Here, the pit density was lower as compared to the AW, AA samples. The distribution of reinforcement particles was uniform. The agglomeration of graphite particles did not happen here. This also reduced the corrosion loss in this weld region. With the reduction in graphite particle concentration, there is a decrease in the number of potential cathodic sites. This has also reduced the rate of corrosion.

The weld region of the STA is shown in Fig. 11d. The weld region shows fine eutectic precipitates that were not continuous. The interspaces between the precipitates were also considerably larger. The microstructure shows the distribution of fine sub microscopic particles throughout the matrix that formed from the particles of the supersaturated solution and the dissolution of secondary intermetallic particles. The pit density was very low in this STA weld region. Due to the discontinuous grain boundary precipitates with large spacing, no continuous chain exists for the corrosion to take place. As a result, the susceptibil- ity to pitting corrosion was reduced. The particle agglomeration of $\mathrm{SiC}$ and graphite did not happen here. This has a role in the reduced corrosion loss of STA joints. The microstructure of the STA joint weld surface reveals no voids and pores. They were eliminated and this has reduced the chances of the pit initiation. During the STA condition, precipitate formation takes place. The fine precipitate enhances the corrosion resistance of the material. The grain structure in the case of the STA condition is also fine, which improves the corrosion resistance. All the above-mentioned reasons played a significant role in the reduction of the corrosion loss in the case of the STA joints.

\section{Conclusions}

The AW(As-welded) joints exhibit more active open circuit potentials as compared to AA, ST, STA joints. The corrosion loss in AW joints is high, compared with other joints. The STA joints exhibit less corrosion loss as compared to the other joints. This is because of the fine grain structure, very few agglomerates of reinforcement particles and the formation of discontinuous Mg2Si precipitates. The corrosion rate of the composite was lower than that of the matrix alloy. The heat treatment resulted in an improved corrosion resistance of the composite. The enhanced pitting corrosion is associated with the pores in the composites. The corrosion rate of the composites decreases due 
to the high bonding strength associated with composites. The solution treatment and ageing (STA) has improved the corrosion resistance characteristics of the STA joint.

\section{REFERENCES}

[1] A. M. Hassan, M. Almomani, T. Qasim, A. Ghaithan. Effect of processing parameters on friction stir welded aluminum matrix composites wear behavior. Materials and Manufacturing Processes 27(12):1419 - 1423, 2012. https://doi.org/10.1080/10426914.2012.700156.

[2] M. Şahin. Joining of aluminium and copper materials with friction welding. The International Journal of Advanced Manufacturing Technology 49:527 - 534, 2010. https://doi.org/10.1007/s00170-009-2443-7

[3] P. Nunes, L. Ramanathan. Corrosion behavior of alumina-aluminum and silicon carbide-aluminum metal-matrix composites. Corrosion 51:610 - 617, 1995. https://doi.org/10.5006/1.3293621

[4] J. F. Mcintyre, R. Conrad, S. Golledge. Technical note: The effect of heat treatment on the pitting behavior of $\mathrm{SiCw} / \mathrm{AA} 2124$. Corrosion 46:902 - 905, 1990. https://doi.org/10.5006/1.3580856

[5] D. Aylor, P. Moran. Effect of reinforcement on the pitting behavior of aluminum-base metal matrix composites. Journal of The Electrochemical Society 132:1277 - 1281, 1985. https://doi.org/10.1149/1.2114101

[6] L. Hihara, R. Latanision. Galvanic corrosion of aluminum-matrix composites. Corrosion 48:546 - 552, 1992. https://doi.org/10.5006/1.3315972

[7] J. Senthilkumar, P. Suresh Mohan Kumar, M. Balasubramanian. Effect of post weld ageing treatment on tensile properties and micro structural characteristics of friction welded AA6061/SiC/Graphite hybrid composites 10:1275 - 1284, 2020. https://doi.org/10.24247/ijmperdapr2020122.

[8] S. Won, B. Seo, J. M. Park, et al. Corrosion behaviors of friction welded dissimilar aluminum alloys. Materials Characterization 144:652 - 660, 2018. https://doi.org/10.1016/j.matchar.2018.08.014.

[9] V. Balasubramanian, J. Senthilkumar, M. Balasubramanian. Optimization of the corrosion behavior of $\mathrm{AA} 7075 \mathrm{Al} / \mathrm{SiCP}$ and $\mathrm{Al} / \mathrm{Al} 2 \mathrm{O} 3$ composites fabricated by powder metallurgy. Journal of Reinforced Plastics and Composites 27(15):1603 - 1613, 2008. https://doi.org/10.1177/0731684407082629.

[10] A. Sharma, V. Mani Sharma, B. Sahoo, et al. Study of nano-mechanical, electrochemical and Raman spectroscopic behavior of Al6061-SiC-Graphite hybrid surface composite fabricated through friction stir processing. Journal of Composites Science 2:32, 2018. https://doi.org/10.3390/jcs2020032

[11] J. Senthilkumar, P. Suresh Mohan Kumar, V. Balasubramanian. Post weld heat treatment of continuous drive friction welded AA6061/SiC/Graphite hybrid composites-an investigation. Materials Research Express 6(12):1265e1, 2019.

https://doi.org/10.1088/2053-1591/ab6407
[12] K. Sri Ram Vikas, V. S. N. Venkata Ramana, R. Mohammed, et al. Influence of post weld heat treatment on microstructure and pitting corrosion behavior of dissimilar aluminium alloy friction stir welds. Materials Today: Proceedings 15:109 - 118, 2019 https://doi.org/10.1016/j.matpr.2019.05.032

[13] N. Sunitha, K. Manjunatha, S. Khan, M. Sravanthi. Study of $\mathrm{SiC} /$ graphite particulates on the corrosion behavior of $\mathrm{Al} 6065$ MMCs using tafel polarization and impedance. SN Applied Sciences 1, 2019. https://doi.org/10.1007/s42452-019-1063-6.

[14] E. Subba Rao, N. Ramanaiah. Influence of heat treatment on mechanical and corrosion properties of aluminium metal matrix composites (AA 6061 reinforced with MoS2). Materials Today: Proceedings 4(10):11270 - 11278, 2017. https://doi.org/10.1016/j.matpr.2017.09.050

[15] R. Loto, A. Adeleke. Corrosion of aluminum alloy metal matrix composites in neutral chloride solutions. Journal of Failure Analysis and Prevention 16:874885, 2016. https://doi.org/10.1007/s11668-016-0157-3.

[16] P. Vijaya Kumar, G. Madhusudhan Reddy, K. Srinivasa Rao. Microstructure, mechanical and corrosion behavior of high strength AA7075 aluminium alloy friction stir welds - Effect of post weld heat treatment, journal $=$ Defence Technology 11(4):362 369, 2015. https://doi.org/10.1016/j.dt.2015.04.003

[17] J. Senthilkumar, M. Balasubramanian, V. Balasubramanian. Effect of metallurgical factors on corrosion behavior of $\mathrm{Al}-\mathrm{SiCp}$ composites fabricated by powder metallurgy. Journal of Reinforced Plastics and Composites 28(9):1087 - 1098, 2009. https://doi.org/10.1177/0731684407087005.

[18] P. P. Trzaskoma. Pit morphology of aluminum alloy and silicon carbide/aluminum alloy metal matrix composites. Corrosion 46(5):402 - 409, 1990. https://doi.org/10.5006/1.3585124.

[19] M. Bhat, M. Surappa, H. Nayak. Corrosion behaviour of silicon carbide particle reinforced 6061/Al alloy composites. Journal of Materials Science 26:4991 4996, 1991. https://doi.org/10.1007/BF00549882

[20] S. Sinhmar, D. K. Dwivedi. Effect of weld thermal cycle on metallurgical and corrosion behavior of friction stir weld joint of AA2014 aluminium alloy. Journal of Manufacturing Processes 37:305 - 320, 2019. https://doi.org/10.1016/j.jmapro.2018.12.001

[21] F. Gharavi, K. A. Matori, R. Yunus, et al. Corrosion evaluation of friction stir welded lap joints of AA6061-T6 aluminum alloy. Transactions of Nonferrous Metals Society of China 26(3):684 - 696, 2016. https://doi.org/10.1016/S1003-6326(16)64159-6

[22] S. Bocchi, M. Cabrini, G. D'Urso, et al. The influence of process parameters on mechanical properties and corrosion behavior of friction stir welded aluminum joints. Journal of Manufacturing Processes 35:1 - 15, 2018. https://doi.org/10.1016/j.jmapro.2018.07.012

[23] A. Vinoth Jebaraj, K. Aditya, T. Sampath Kumar, et al. Mechanical and corrosion behaviour of aluminum alloy 5083 and its weldment for marine applications. Materials Today: Proceedings 22:1470 - 1478, 2020. https://doi.org/10.1016/j.matpr.2020.01.505. 
[24] N. Ramesh, V. Senthil Kumar. Experimental erosion-corrosion analysis of friction stir welding of AA 5083 and AA 6061 for sub-sea applications. Applied Ocean Research 98:102121, 2020.

https://doi.org/10.1016/j.apor.2020.102121.
[25] S. Li, H. Dong, L. Shi, et al. Corrosion behavior and mechanical properties of $\mathrm{Al}-\mathrm{Zn}-\mathrm{Mg}$ aluminum alloy weld. Corrosion Science 123:243 - 255, 2017. https://doi.org/10.1016/j.corsci.2017.05.007. 